\title{
Challenges surrounding penile prostheses insertion following acute priapism
}

\author{
Alex Tatem ${ }^{1}$, Jason R. Kovac ${ }^{2}$ \\ ${ }^{1}$ Department of Urology, Indiana University, Indianapolis, Indiana, USA; ${ }^{2}$ Men's Health Center, Indianapolis, Indiana \\ Correspondence to: Dr. Jason R. Kovac, MD, PhD, FACS, FRCSC. Men’s Health Center, 8240 Naab Road, Suite 220, Indianapolis, Indiana 46260, \\ USA. Email: jkovac@urologyin.com. \\ Comment on: Moore J, Whelan TF, Langille GM. The use of penile prostheses in the management of priapism. Transl Androl Urol 2017;6:S797-803.
}

Submitted Nov 11, 2017. Accepted for publication Nov 13, 2017.

doi: $10.21037 /$ tau.2017.11.19

View this article at: http://dx.doi.org/10.21037/tau.2017.11.19

The role of immediate penile prosthesis placement in the management of patients suffering from acute priapism is controversial. Multiple temporal and intra-operative factors influence the decision of physicians to offer the option of early penile prosthesis placement. Although the duration of an ischemic priapism episode is the most predictive factor for determining long-term functional outcomes, treatments can range from conservative (observation) to aggressive (penile prosthesis insertion). In either situation, it is important to educate patients that many who present within 24 hours of priapism onset will still likely develop some form of lasting erectile dysfunction (ED) (1).

Factors that contribute to decisions regarding intervention can be as simple as who the urologist is on call. Prosthetic urologists are much more likely to offer early penile implantation given their familiarity with the literature and knowledge about device placement techniques. However, in spite of this, the most significant barrier that will ultimately affect clinical decision-making in the acute scenario is strictly logistical. In the United States, insurance coverage for placement of a penile prosthesis is almost universally predicated on obtaining prior authorization, which is very difficult (if not impossible) to obtain in an acute setting. While Moore et al. (2) cite a 2013 study where the average malleable device cost was reported as being 3,850 USD, more recent pricing data from manufacturers (American Medical Systems and Coloplast), place current retail costs at more than twice that (3). Without insurance approval, patients are at risk for costs being transferred directly to them. Not just for the device but also for the pre- and post-operative stay along with all intra-operative supplies. Consequently, at our institution, we have adopted a modified management strategy that has been optimized for our practice environment.

At the time of acute presentation, patients are counseled about the risks of lasting ED due to their priapism and presented with the option of penile prosthesis placement. In all cases, priapism is treated as per standard protocol [as summarized in (4)]. Standard sterile corporal irrigations and phenylephrine injections are performed at the bedside while any shunt procedures, if required, are performed in the operating room. Patients are then placed on prophylactic antibiotics to reduce the risk of infection and given educational materials regarding prosthesis placement while insurance approval is submitted. Once prior authorization has been obtained, penile prosthesis placement is performed electively. This is typically done within a 2 - to 3 -week window to minimize the onset corporal fibrosis. Individual factors are always considered. For example, a patient who experiences a first-episode priapism at the age of 30 years old (after "borrowing" a friend's penile injection solution) is much more likely to be managed conservatively compared to the 70-year-old patient with long standing ED who has been on penile injection therapy for 10 years. Such a compromise has allowed the authors to provide definitive care for appropriate patients while avoiding the complications of corporal fibrosis post-priapism as well as penile shortening and ED that commonly arise in this challenging patient population (5). 


\section{Acknowledgements}

None.

\section{Footnote}

Conflicts of Interest: The authors have no conflicts of interest to declare.

\section{References}

1. Zacharakis E, Raheem AA, Freeman A, et al. The efficacy of the T-shunt procedure and intracavernous tunneling (snake maneuver) for refractory ischemic priapism. J Urol

Cite this article as: Tatem A, Kovac JR. Challenges surrounding penile prostheses insertion following acute priapism. Transl Androl Urol 2017;6(Suppl 5):S804-S805. doi: 10.21037/tau.2017.11.19
2014;191:164-8.

2. Moore J, Whelan TF, Langille GM. The use of penile prostheses in the management of priapism. Transl Androl Urol 2017;6:S797-803.

3. Tausch TJ, Zhao LC, Morey AF, et al. Malleable penile prosthesis is a cost-effective treatment for refractory ischemic priapism. J Sex Med 2015;12:824-6.

4. Kovac JR, Mak SK, Garcia MM, et al. A pathophysiologybased approach to the management of early priapism. Asian J Androl 2013;15:20-6.

5. Zacharakis E, Garaffa G, Raheem AA, et al. Penile prosthesis insertion in patients with refractory ischaemic priapism: early vs delayed implantation. BJU Int 2014;114:576-81. 